\title{
REFLEXÕES SOBRE A EDUCAÇÃO DE JOVENS E ADULTOS: CONTRADIÇÕES E POSSIBILIDADES
}

P. C. M. FREIRE ${ }^{*}$ e M. E. F. CARNEIRO
'Instituto Federal de Educação, Ciência e Tecnologia de Goiás
2Pontifícia Universidade Católica de Goiás
pocrismf@yahoo.com.br ${ }^{*}$
Artigo submetido em outubro/2015 e aceito em dezembro/2015
DOI: $10.15628 /$ rbept.2016.3469

\section{RESUMO}

A educação como direito deve ser estendida e garantida a todos. Há pouco mais de cem anos que a sua universalização passou a ser discutida e implementada no Brasil. O objetivo deste artigo foi desvelar as contradições na Educação de Jovens e Adultos (EJA) a partir da perspectiva materialista histórico-dialética. Em um primeiro momento, foi apresentado um histórico da EJA no Brasil e em seguida realizadas algumas reflexões sobre as contradições e possibilidades nesta modalidade de ensino. O trabalho enquanto categoria foi considerado como princípio educativo por excelência. Na EJA, a integração entre educação e trabalho pode representar um caminho de superação da exploração capitalista, ou seja, um poderoso instrumento de formação para a ação política transformadora. Por se tratar de uma investigação em seu estágio inicial, as reflexões apresentadas são ainda parciais e transitórias.

PALAVRAS-CHAVE: Políticas Públicas, Educação de Jovens e Adultos, Trabalho e Sociedade capitalista.

\section{REFLECTIONS ON ADULT EDUCATION: CONTRADICTIONS AND POSSIBILITIES}

\begin{abstract}
Education as a right should be extended and maintained at all. Just over one hundred years that its universalization began to be discussed and implemented in the Brazil. The aim of this paper was to reveal the contradictions in the adult education from the historical and dialectical materialism. At first, a history of adult education was introduced in Brazil and then made some reflections on the contradictions and possibilities in this
\end{abstract}

type of education. The work as a category was considered as an educational principle par excellence. In adult education, the integration between education and work may represent an overcoming of capitalist exploitation path, ie a powerful training tool for transforming political action. Because it is an investigation in its early stages, the reflections presented are still partial and transient.

KEYWORDS: Public Policy, Adult Education, Work and Capitalist society. 


\section{INTRODUÇÃO}

A educação como direito universal estendido a todos brasileiros é um marco recente. Historicamente, a maior parte da população brasileira ficou excluída do acesso à educação, sendo que

[...] a instrução popular [...] se desenvolveu precariamente durante todo o Império, século XIX e grande parte do período republicano. [...] O censo de 1890 informava a existência de $85,21 \%$ de iletrados na população total brasileira (PAIVA, 1985, p. 63-85).

Há pouco mais de cem anos que a universalização da educação passou a ser discutida e implementada no Brasil. Corroborando com esta posição, Shiroma e Lima Filho (2011) afirmam que

[...] historicamente, em nosso país, as políticas educacionais não favoreceram que alunos das classes trabalhadoras realizassem um percurso educacional capaz de garantir o direito à conclusão da educação básica com formação integral. Ao contrário, a história de nossa formação social traz as marcas do passado colonial e escravocrata, da configuração de um capitalismo tardio e subalterno, de uma burguesia aferrada à prática de ações patrimonialistas sobre o Estado, privatizando o público a serviço dos interesses das elites políticas e econômicas. Assim, ao longo dos anos, a desigualdade e a exclusão social foram se ampliando no Brasil, resultando daí grande contingente da população que vive em situação de pobreza, que não concluiu a trajetória escolar e nem possui formação profissional qualificada (SHIROMA; LIMA FILHO, 2011, p. 727-728).

Infelizmente, ainda nos dias atuais, parte da população brasileira não tem usufruído o direito à educação. De acordo com o censo de 2010 realizado pelo Instituto Brasileiro de Geografia e Estatística (IBGE), o percentual de pessoas sem instrução ou com o fundamental incompleto era de $50,2 \%$ (IBGE, 2010).

A Pesquisa Nacional por Amostra de Domicílios (PNAD) de 2014 apontou que 13 milhões de brasileiros são analfabetos. A taxa de analfabetismo mostrou-se maior entre jovens, adultos e idosos em todas as regiões do país. Entre aqueles de 20 a 59 anos de idade, a taxa de analfabetismo foi de $14 \%$ e entre os idosos (60 anos ou mais de idade) foi de $23,9 \%$ (IBGE, 2014).

Paradoxalmente a esta realidade, já em 2013 foi observado um decréscimo no quantitativo de matrículas da educação básica no valor de $1 \%$, o equivalente a 502.602. O número de alunos matriculados na Educação de Jovens e Adultos (EJA) também sofreu uma redução. A EJA apresentou queda de 3,4\% (134.207), totalizando 3.772.670 matrículas. Deste total, 2.447 .792 $(64,9 \%)$ estão no ensino fundamental (inclui EJA integrado à educação profissional e Projovem Urbano) e 1.324.878 (35,1\%) no ensino médio (inclui EJA integrado à educação profissional) (INEP, 2013).

Os motivos da evasão escolar pelos alunos da EJA são diversos, como a impossibilidade de conciliar trabalho e estudo, questões familiares, dificuldade de acesso à escola, entre outros. Entretanto, na sociedade capitalista em que vivemos uma das principais causa da evasão é o trabalho. 
O trabalho ao caracterizar o gênero humano, como categoria ontológica é um dos elementos fundamentais. Este se destaca como sendo o fundante e o decisivo, ou seja, representa a capacidade de transformar a natureza e de produzir bens necessários à vida e à reprodução humana. É um ato consciente com finalidade e como atividade primeira sob a qual se fundamenta a consciência, a linguagem, todas as relações sociais e a práxis humana. Representa o único laço de união entre as forças produtivas e a sua própria existência (COSTA, 1995; MARX, ENGELS, 2002).

Marx e Engels (2002) já apontavam a importância da integração entre trabalho e educação na sociedade de divisão de classes. $O$ trabalho enquanto atividade de autodesenvolvimento e autorealização da existência humana é uma necessidade essencial de efetivar o intercâmbio material entre o homem e a natureza e, portanto, de manter a vida humana. Já a educação representa um instrumento do processo de humanização.

Por meio do trabalho, o homem produz valores de uso ao apropriar-se dos elementos da natureza de forma intencional e planejada. No entanto, o trabalho nas sociedades baseadas na propriedade privada e na divisão em classes sociais antagônicas, como é a nossa sociedade capitalista, também é fonte de exploração, desigualdade e estranhamento.

Para Marx, o estranhamento é quando há a apropriação privada do produto do trabalho por outro indivíduo que não seja o trabalhador-produtor. O trabalho enquanto elemento de humanização é degradado, torna-se alheio, hostil e aliena o trabalhador e o produto (COSTA, 1995).

Deste modo, a partir da matriz materialista histórico-dialética e do levantamento e da análise de fontes primárias e secundárias, em um primeiro momento, apresentaremos um breve histórico da EJA no Brasil e em seguida algumas reflexões sobre as contradições presentes no modo de produção capitalista e possibilidades em torno desta modalidade de ensino.

O método materialista histórico-dialético proposto por Marx inclui o entendimento do fenômeno, com a análise da totalidade de seus aspectos, de suas interações e interdependências para compreensão do mundo e como concepção científica da realidade, que se apóia na matéria, na dialética e na prática social (BRZEZINSKI; CARNEIRO; BRITO, 2006).

Tal matriz implica em colocar o pesquisador numa relação com o objeto capaz de extrair dele, múltiplas determinações. No processo de investigação, o sujeito é essencialmente ativo, para apreender não a aparência ou a forma dada do objeto, mas a sua essência, a sua estrutura e a sua dinâmica, além de estabelecer abstrações, o concreto pensado (NETTO, 1989).

Andriani e Rosa (2002, p. 260-261) afirmam que

[...] a produção de Karl Marx (1818-1883) está intimamente relacionada ao momento histórico em que viveu e desenvolveu seu pensamento. Assim, sua obra é fortemente determinada pelos acontecimentos políticos, econômicos e históricos em que está inserido, bem como por um forte comprometimento em relação à classe trabalhadora. [...] $O$ grande avanço de Marx consistiu em partir da explicação dialética de Hegel, aplicando a ela uma concepção materialista, o que implica dizer que a marca de seu pensamento é a perspectiva materialista dialética sob a qual propõe a compreensão da realidade da sociedade e do homem. 
Para analisar um fenômeno social devemos estudar a sua totalidade. Não há como usar um microscópio, como nos fenômenos naturais, em que se estudam as partes que constituem um fenômeno para depois encontrar na essência e no fundamento, as contradições responsáveis pelo desenvolvimento da formação material organizada (TRIVIÑOS, 1987).

\section{HISTÓRICO DA EJA NO BRASIL}

Em nossa historicização iniciaremos pela tentativa de reconhecimento da EJA como um direito a partir da década de 1930, com destaque para as campanhas de alfabetização que aconteceram nos anos de 1940 e 1950.

Ao final da década de 1950, o educador pernambucano Paulo Freire iniciou a sistematização de seu método de ensino para a alfabetização de adultos. Suas primeiras experiências de aplicação do método se iniciaram na cidade de Angicos, no Rio Grande do Norte, em 1962, tendo a participação de 300 trabalhadores que foram alfabetizados em 45 dias. 0 método freireano estimulava a compreensão do registro escrito a partir do conhecimento do aluno e da conscientização da população sobre a realidade brasileira de maneira dialógica. Considerava que a educação, para ser transformadora e emancipadora, necessitava considerar e respeitar as pessoas, suas culturas e modo de vida.

Em 1970, surgiram os movimentos de cultura popular, o Movimento Brasileiro de Alfabetização (MOBRAL), o ensino supletivo dos governos militares e a Fundação Educar da Nova República.

Já no Governo Collor, as políticas neoliberais de reforma do Estado num contexto de crise financeira provocaram mudanças na educação básica e acabaram priorizando a educação fundamental das crianças, deixando de lado mais uma vez a EJA. Em 1991, o então ministro da Educação, Prof. José Goldemberg deu a seguinte declaração:

"O adulto analfabeto já encontrou seu lugar na sociedade. Pode não ser um bom lugar, mas é o seu lugar. Vai ser pedreiro, vigia de prédio, lixeiro ou seguir outras profissões que não exigem alfabetização. Alfabetizar o adulto não vai mudar muito sua posição dentro da sociedade e pode até perturbar [...] (Jornal do Brasil, Rio de Janeiro, 12 de dezembro, 1991)."

Neste período, o discurso da inclusão foi substituído pelo discurso da exclusão com estabelecimento de prioridades a partir da restrição de direitos ditos como universais, mantendo a gratuidade da educação pública a jovens e adultos, mas suprimindo a sua obrigatoriedade. Durante o governo de Fernando Henrique Cardoso houve a alteração dos incisos I e II do artigo 208 da Constituição de 1988:

\footnotetext{
"O dever do Estado com a educação será efetivado mediante a garantia de:

I - ensino fundamental, obrigatório e gratuito, inclusive para os que a ele não tiveram acesso na idade própria;

II - progressiva extensão da obrigatoriedade e gratuidade ao ensino médio."
}

A alteração do artigo 208 da Constituição se deu com a aprovação da Emenda Constitucional no 14 de 1996 que estabelecia: 
"Art. 2ํ É dada nova redação aos incisos I e II do art. 208 da Constituição:

I - ensino fundamental obrigatório e gratuito, assegurado, inclusive, sua oferta gratuita para todos os que a ele não tiveram acesso na idade própria;

II - progressiva universalização do ensino médio gratuito".

Ainda neste governo, houve a criação do Fundo de Manutenção e Desenvolvimento do Ensino Fundamental e Valorização do Magistério (FUNDEF) que excluiu jovens e adultos, não considerando as matrículas no ensino supletivo no cômputo dos alunos financiados por esse fundo nas redes de ensino fundamental dos Estados, Municípios e do Distrito Federal (HADDAD; XIMENES, 2014).

A própria Lei de Diretrizes e Bases (LDB) (Lei no 9.394) de 1996 que definiu a EJA como aquela educação destinada àqueles que não tiveram acesso ou continuidade de estudos no ensino fundamental e médio na idade regular, assegurando a gratuidade aos jovens e aos adultos. Oportunidades educacionais apropriadas deveriam ser oferecidas, considerando as características do alunado, seus interesses, condições de vida e de trabalho, mediante cursos e exames (BRASIL, 1996). Entretanto, as ações empreendidas neste sentido, relegaram esta forma de educação a segunda categoria, tratando-a como modalidade específica, de maneira parcial e em alguns momentos interpretando-a, até mesmo, como Ensino Supletivo (HADDAD; XIMENES, 2014).

Em 1997, a partir do Decreto 2.208 que regulamentou o inciso 2ㅇ do artigo 36 e os artigos 39 a 42 da LDB, foi estabelecido que os sistemas de ensino assegurariam oportunidades educacionais apropriadas aos jovens e adultos; o poder público viabilizaria o acesso e a permanência do trabalhador na escola e que a EJA aconteceria de forma articulada com a educação profissional. Ressaltamos que este decreto representou uma conquista decorrente de lutas de professores, alunos e comunidade escolar pelo direito a EJA.

Tal decreto foi substituído pelo 5.154/2004 que regulamentou a Educação Profissional e estabeleceu a integração entre Educação Profissional e Educação Básica, além disso, a articulação dessa modalidade com a EJA e/ou com outras modalidades que contemplassem estratégias de educação continuada. Este ensino poderia ser realizado em escolas do ensino regular, em instituições especializadas ou nos ambientes de trabalho.

A obrigação da implantação de cursos profissionais na modalidade EJA nos Centros Federais de Educação Tecnológica (CEFET) foi estabelecida pela Portaria 2.080/2005. Ainda neste mesmo ano, a Portaria 2.080 foi ratificada pelo Decreto 5.478, que instituiu o Programa de Integração da Educação Profissional ao Ensino Médio na Modalidade Educação de Jovens e Adultos.

O Decreto 5.840/2006 revogou o de número 5.478 e alterou o nome para Programa Nacional de Integração da Educação Profissional com a Educação Básica na Modalidade de Educação de Jovens e Adultos (PROEJA) com a inclusão do ensino fundamental. O programa passou a ser ofertado nos sistemas públicos de ensino e nas instituições do Sistema Nacional de Aprendizagem, mas sendo mantida a obrigatoriedade para a Rede Federal.

Em 2006, foi publicado o Documento Base do PROEJA que indicava a intenção governamental de consolidar o programa como política pública para a Educação Profissional e EJA, estabelecendo a elevação da escolaridade dos trabalhadores e a integração dos conhecimentos científicos aos conhecimentos técnicos. 
A partir de então, ficou definido, por exemplo, que as instituições federais de educação profissional deveriam implantar cursos e programas regulares do PROEJA até o ano de 2007, sendo que já em 2006, no mínimo dez por cento do total das vagas de ingresso da instituição (tendo como referência o quantitativo de matrículas do ano anterior) seriam destinadas a esse público. A expansão da oferta deveria ocorrer a partir de 2007 e esta ampliação deveria estar incluída no plano de desenvolvimento institucional (PDI) da instituição federal de ensino.

Somado a isso, a emenda constitucional no 53/2006, criou o Fundo de Manutenção e Desenvolvimento da Educação Básica e de Valorização dos Profissionais da Educação (FUNDEB), o qual passou a contemplar a EJA no cômputo das matrículas consideradas para efeito de distribuição de recursos, após 10 anos de atraso em relação ao FUNDEF.

A emenda no 59/2009 ampliou a obrigatoriedade escolar na faixa considerada regular, dos quatro a dezessete anos de idade, assegurando inclusive oferta gratuita para todos aqueles que não tiveram acesso na idade própria. A partir de então, houve o reconhecimento constitucional do direito de jovens e adultos a toda a educação básica.

A EJA também esteve presente no Plano Nacional de Educação (PNE) de 2001 a 2010 e no PNE de 2011 a 2020 (GRACINDO, 2011). No primeiro Plano foram estabelecidas 26 metas, no entanto, no novo plano, estas foram reduzidas para apenas duas. Mais do que isso, estas duas metas são tímidas como poderemos constatar a seguir.

No novo PNE, as duas metas para a EJA se referem ao quadro de analfabetismo da população acima de 15 anos e a necessidade de ampliação da EJA na forma integrada à educação profissional. Para o analfabetismo, a meta prevê a elevação da taxa de alfabetização das pessoas com 15 anos ou mais para 93,5\% até 2015 e até 2020 a erradicação total do analfabetismo. Neste mesmo período reduzir em $50 \%$ o analfabetismo funcional. Quanto à ampliação de matrículas de jovens e adultos na forma integrada à educação profissional nos anos finais do ensino fundamental e médio, a meta estabelece um mínimo de 25\% das matrículas (BRASIL, 2014).

A partir deste breve histórico, notamos que a EJA passou por momentos de avanços e retrocessos. Muitas vezes, esta modalidade de ensino ficou restrita apenas às formalidades legais. A erradicação do analfabetismo com a oferta de EJA ainda é um sonho distante, em decorrência da omissão do Estado em relação à garantia do direito à educação. Haddad e Ximenes (2014, p. 255), salientam que após 25 anos da Constituição de 1988 e 17 anos da LDB, "a EJA ainda continua na sala de espera".

\section{CONTRADIÇÕES E POSSIBILIDADES NA EJA}

De acordo com Marx, as contradições constituem a força motriz no interior do desenvolvimento de cada fenômeno e por isso a sua análise representa uma via de conhecimento da realidade, um método de aplicação conseqüente do princípio da historicidade. Desta forma, buscamos refletir sobre algumas contradições e possibilidades na EJA.

Nos dias atuais a EJA é caracterizada tanto pelo jovem e adulto que ficou afastado por vários anos da escola e depois retorna, como por jovens repetentes que ao atingirem a faixa etária permitida passam a frequentar a EJA, sem que tivessem deixado de estudar na idade regular (MOURA, 2005). Na maioria das vezes, esse público tem que conciliar estudo e trabalho, entretanto, muitas vezes o trabalho interfere nos estudos e vice-versa. 
Os alunos sentem-se responsabilizados pelas condições sociais em que se encontram e anseiam por melhores condições de vida que podem ser conquistadas a partir do trabalho, que, hoje, é orientado pelas necessidades humanas, pela reprodução social e pela propriedade privada.

Na EJA os estudantes estão inseridos no modo de produção capitalista, em que a força de trabalho é mercadoria de troca e o trabalho passa a ser o instrumento de sobrevivência material. O capitalismo se fundamenta na relação de exploração da maioria, os trabalhadores, pela minoria, os donos dos meios de produção, ou seja, entre aqueles que produzem e aqueles que se apropriam do produto (BERNARDO, 1998). Quando parte da força de trabalho dispendida pelo trabalhador, não é remunerada pelo dono do meio de produção temos a mais-valia, principal fonte de lucro para estes detentores (MARTINS, 1980).

Nesta relação antagônica e contraditória de exploração de uma classe sobre outra, temos o motor do próprio sistema capitalista. Os meios e bens de produção, isto é, a matéria-prima, as ferramentas, as máquinas, a indústria e o produto final é propriedade da classe dominante (da burguesia) que para gerar riquezas e lucro explora a classe menos favorecida, àqueles que não são donos desses meios e dispõe apenas de sua força de trabalho (MARX, 1989).

Deste modo, na sociedade capitalista a forma elementar de produção e distribuição de bens é a mercadoria, considerada a célula econômica da sociedade burguesa e uma unidade dialética entre valor de uso e valor de troca (MARX; ENGELS, 2002). A partir disso, a formação para o trabalho passou a ser sinônimo de formação profissional, em que o trabalho passa a ter a função econômica de produção de bens. Na lógica neoliberal do capitalismo, deu-se o avanço da privatização da educação convertendo-a em uma das mercadorias.

Segundo Frigotto (2005), o trabalho, a propriedade, a ciência e a tecnologia deixam de ter centralidade como valores de uso para os trabalhadores e são apropriadas pelos capitalistas para se constituírem em valores de troca. Neste sentido:

[...] A força de trabalho expressa sua centralidade ao se transformar em produtora de valores de troca, com o fim de gerar mais lucro ou mais valor para os capitalistas. O trabalho, então, de atividade produtora imediata de valores de uso para os trabalhadores, se reduz à mercadoria força de trabalho e tende a se confundir com emprego. O capital detém como propriedade privada, de forma crescente, os meios e instrumentos de produção. A classe trabalhadora detém apenas sua força de trabalho para vender. Ao capitalista interessa comprar o tempo de trabalho do trabalhador ao menor preço possível, organizá-lo e gerenciá-lo de tal sorte que ao final de um período de trabalho - jornada, semana ou mês - o pagamento em forma de salário represente apenas uma parte de tempo pago e a outra se transforme em ganho do capitalista ou um sobrevalor [...] (FRIGOTTO, 2005, p. 4).

Para Marx,

[...] o processo de trabalho é atividade orientada a um fim, para produzir valores de uso, apropriação do natural para satisfazer a necessidades humanas, condição universal do metabolismo entre homem e natureza, condição natural eterna da vida humana e, portanto, independente de qualquer forma de vida, sendo antes igualmente comum a todas as suas formas sociais [...] (MARX, 2003, p.105). 
A união entre educação e trabalho como uma das possibilidades a mais de superação da exploração capitalista, como instrumento de formação para a ação política transformadora, que já era preconizada por Marx e Engels (2002) e, ainda hoje, se apresenta como desafio. A formação geral e técnica constituiriam a base da autonomia do operário no processo de produção, sendo uma autonomia que permitiria controlar o processo de produção e reprodução dos conhecimentos científicos e técnicos, garantindo também o acesso ao saber, à ciência e à cultura técnica.

O ensino concebido como educação básica e articulado ao mundo do trabalho, para Frigotto (2005), não deve atender somente ao imediatismo do mercado do trabalho. A formação profissional específica, para ser efetiva, deve ter como condição prévia a educação básica (fundamental e média) e relacioná-la às mudanças técnico-científicas do processo produtivo imediato.

Na sociedade moderna em que vivemos a educação não pode responder apenas às necessidades adaptativas, funcionais, de treinamento do trabalhador exigidas pelo mercado de trabalho. Deve-se construir uma educação que tenha preocupação fundamental com o trabalho em sua forma mais ampla, que reflita sobre as contradições da organização deste na sociedade, bem como as possibilidades de superação das condições adversas.

O trabalho como princípio educativo por excelência envolve a coordenação dos estudos com o trabalho produtivo e físico (trabalho manual, trabalho fabril), sendo que esta união colabore com a derrubada das condições capitalistas de exploração e garanta a inserção dos educandos na produção material, no contexto e nas condições da produção, ao invés da escola recriar, imitativamente, o modo de produção (MARX, 1989).

Marx e Engels também defendiam que a educação deveria incluir formação geral e formação científica, que são necessárias à compreensão de todo processo de produção. A educação dos jovens deveria englobar a formação intelectual, corporal e politécnica (LOMBARDI, 2010).

A base material da manutenção da vida a partir do trabalho deve estruturar todo o processo educacional, pois os homens se reconhecem na medida em que produzem sua existência. Uma educação integrada é uma educação que tenha como perspectiva a totalidade, que não seja apenas uma união das partes, mas uma análise do real, do concreto. Para Marx (2003, p. 256) "o concreto é concreto porque é a síntese das múltiplas determinações, isto é, unidade do diverso".

A integração entre educação profissional e educação básica já era defendida por Marx e Engels ao apontarem que a formação geral e técnica fossem a base da autonomia do operariado no processo de produção, com o ensino politécnico preparando-o para atuar no processo administrativo e também no produtivo (LOMBARDI, 2010).

Na perspectiva de superação das contradições da EJA, o PROEJA implantado pelo Decreto 5.840/2006 pode apresentar-se como uma possibilidade, também em certa medida, para a construção de novas relações sociais e de trabalho. É um programa educacional que pretende, no âmbito legal, integrar o Ensino Médio e a Educação Profissional, considerando a especificidade da EJA (jovens e adultos trabalhadores), buscando a superação da dualidade trabalho manual e intelectual, assumindo o trabalho na sua perspectiva criadora, de formação humana e de trabalho não alienado (BRASIL, 2007). 


\section{CONSIDERAÇÕES FINAIS}

O presente artigo aborda categorias da minha pesquisa de doutorado em andamento no Programa de Pós-Graduação em Educação da Pontifícia Universidade Católica de Goiás (PUC-GO). Por se tratar de uma investigação em seu estágio inicial, as reflexões apresentadas podem ser ainda parciais e transitórias.

No Brasil, como consequência de longos períodos de exclusão, da falta de reconhecimento jurídico-social demonstrado pelo processo histórico e da omissão do Estado, a EJA não foi e nem é uma das prioridades educacionais do país. Esta modalidade de ensino ainda não representa um processo de emancipação e de transformação social e as contradições entre trabalho, educação e o modo de produção capitalista ainda persistem.

A educação básica pautada no princípio da igualdade de direito ao conhecimento produzido, pode representar a conquista do acesso e permanência na escola daqueles que pelos mais diversos motivos econômicos, políticos e sociais, não chegaram a frequentá-la na idade regular ou dela foram excluídos (MACHADO, 2008).

Portanto, a fim de que o direito à educação seja garantido e aconteça de forma efetiva, consideramos como primordial a implantação e implementação de políticas públicas e que realmente atendam aos interesses e necessidades de jovens e adultos, que permitam a integração entre educação e trabalho, e que se constituam em arcabouço para a superação das contradições na sociedade capitalista.

\section{REFERÊNCIAS}

1. ANDRIANI, A. G. P.; ROSA, E. Z. Psicologia Sócio - Histórica: Uma Tentativa de Sistematização metodológica e Epistemológica. In: Kahhale, E.M.P. (org.), A Diversidade da Psicologia: uma construção teórica. São Paulo: Cortez, 2002.

2. BERNARDO, João. Estado: a silenciosa multiplicação do poder. São Paulo: Escrituras Editora, 1998, 144p.

3. BRASIL. Constituição da República Federativa do Brasil, 1988. Brasília, DF: 1988. Disponível em: < http://www.planalto.gov.br/ccivil_03>. Acesso em: 10 fev. 2015.

4. BRASIL. Ministério da Educação. LDB. Lei 9394/96 - Lei de Diretrizes e Bases da Educação Nacional. Brasília, DF, 1996. Disponível em: <www.planalto.gov.br>. Acesso em: 01 fev. 2015.

5. BRASIL. Ministério da Educação. Documento Base - PROEJA - Programa Nacional de Integração da Educação Profissional a Educação Básica na Modalidade de Educação de Jovens e Adultos. Formação Inicial e continuada/ Ensino Fundamental. Brasília, DF: SETEC, 2007. Disponível em: <portal.mec.gov.br/setec>. Acesso em: 06 jan. 2015.

6. BRASIL. Ministério da Educação. Planejando a próxima década: Construindo os Planos de Educação. Brasília, DF: SASE, 2014. Disponível em: <http://pne.mec.gov.br/>. Acesso em: 06 jan. 2015.

7. BRZEZINSKI, I.; CARNEIRO, M. E. F.; BRITO, W, A. de. Pesquisa em Avaliação Institucional: uma experiência na Universidade Estadual de Goiás. Revista da Rede de Avaliação Institucional da Educação Superior, v. 11, n. 2, p. 103-133, 2006.

8. COSTA, S. O trabalho como elemento fundante da humanização. Revista Estudos, Goiânia: 
UCG, v. 22, n. 3/4, p. 171-188, 1995.

9. FRIGOTTO, G. Concepções e mudanças no mundo do trabalho e o ensino médio. In: FRIGOTTO, G.; CIAVATTA, M.; RAMOS, M. (Org.). Ensino médio integrado: concepções e contradições. São Paulo: Cortez, 2005. p.1-16.

10. GRACINDO, R. V. Educação de Jovens e Adultos e o PNE 2011-2020: avaliação e perspectivas. In: DOURADO, L. (Org.). Plano Nacional de Educação (2011-2020): Avaliação e Perspectivas. 2 ed. Belo Horizonte: Ed. UFG/Autêntica, 2011. p.137-192.

11. HADDAD, S.; XIMENES, S. A educação de pessoas jovens e adultas na LDB: um olhar passados 17 anos. In: BRZEZINSKI, I. (Org.). LDB/1996 Contemporânea: contradições, tensões e compromissos. São Paulo: Ed. Cortez, 2014. p. 233-255.

12. INSTITUTO BRASILEIRO DE GEOGRAFIA E ESTATÍ́sTICA. IBGE. Censo Demográfico 2010, 2010. $65 \mathrm{p}$.

13. INSTITUTO BRASILEIRO DE GEOGRAFIA E ESTATístICA. IBGE. Pesquisa Nacional por Amostra por domicílios, 2014.

14. INSTITUTO NACIONAL DE ESTUdOS E PESQUISAS EDUCACIONAIS ANÍSIO TEIXEIRA. Censo Escolar da Educação Básica 2013: resumo técnico/ Instituto Nacional de Estudos e Pesquisas Educacionais Anísio Teixeira. Brasília: O Instituto, 2014. 39 p.

15. JORNAL DO BRASIL, Rio de Janeiro, 1991.

16. LOMBARDI, J. C. Reflexões sobre educação e ensino na obra de Marx e Engels. 2010. 377 f. Tese (Livre Docência em Filosofia e História da Educação) - Faculdade de Educação, Universidade Estadual de Campinas, Campinas, 2010.

17. MACHADO, M. M. Formação de professores para EJA: uma perspectiva de mudança. Revista Retratos da Escola, v. 2, n. 2-3, p. 161-174, 2008.

18. MARTINS, J. de S. A sujeição da renda da terra ao capital e o novo sentido da luta pela reforma agrária. In: FÉLIX, M. et al. A classe operária e seu partido. Rio de Janeiro: Ed. Civilização Brasileira, 1980.

19. MARX, K. Manuscritos Econômicos e Filosóficos. Lisboa: Edições 70, 1989.

20. MARX, K.; ENGELS, F. A Ideologia Alemã. Tradutor Luis Cláudio de Castro e Costa. Martins Fontes: São Paulo, 2002. 119 p.

21. MARX, K. Contribuição à crítica da Economia Política. 3. ed. São Paulo: Martins Fontes, 2003.

22. MOURA, D. H. Algumas considerações críticas ao programa de integração da educação profissional ao ensino médio na modalidade de educação de jovens e adultos - PROEJA. In: II Colóquio internacional políticas e práticas curriculares: impasses tendências e perspectivas. ANAIS... João Pessoa: UFPB, 2005.

23. NETTO, J.P. Introdução ao método da teoria social. UFRJ: Serviço Social, 1989.

24. PAIVA, V. Educação Popular e Educação de Adultos. São Paulo: Edições Loyola, 1985.

25. SHIROMA, E. O.; LIMA FILHO, D. L. Trabalho docente na Educação Profissional e Tecnológica e no PROEJA. Educação \& Sociedade, Campinas, v. 32, n.116, 2011.

26. TRIVIÑOS. A. N. S. Introdução à pesquisa em ciências sociais: a pesquisa qualitativa em educação. São Paulo: Atlas, 1987. 